\title{
La novela de formación de Hermann Hesse como testimonio de una identidad y una filosofía de la vida: la construcción del outsider en El lobo estepario*
}

\author{
IRENE MaRTínez SAHUQUILLO \\ Universidad de Salamanca
}

\begin{abstract}
Hermann Hesse's Bildungsroman as a document for the study of an identity and a view of life: The construction of the outsider in The Steppenwolf
\end{abstract}

\section{RESUMEN ABSTRACT}

El propósito de este artículo es analizar la novela de formación de Hermann Hesse y,

en particular, El lobo estepario, como un documento de carácter testimonial, tanto exponente de una cosmovisión profundamente romántica y rebelde frente a la sociedad contemporánea como ilustrativo de una construcción de identidad específica, la del outsider que se aparta del mundo y que convierte su autoexilio

voluntario en un signo de elección. Tras defender la relevancia de la literatura para el análisis histórico y sociológico,

destacando en especial su valor como reflejo de un clima moral o Zeitgeist y como vehículo para la expresión de ideas, abordo

la importancia de la novela de Hermann Hesse entendida como un tipo singular de

Bildungsroman en la que convergen la tradición romántica y nuevas formas de subjetivismo. A continuación, analizo El lobo estepario, interpretado como testimonio confesional, análisis y manifiesto de un artista outsider que construye su identidad contra la sociedad burguesa de su tiempo y

que anticipa la contracultura de los '60.
The purpose of this paper is to study Hermann Hesse's Bildungsroman and, in particular, The Steppenwolf, as a document of testimonial character expressing a deeply romantic worldview, in revolt against contemporary society, and displaying an specific identity construction, that of the outsider who keeps away from the world and makes of this voluntary self-exile a sign of distinction. After arguing in favor of the relevance of literature for both historical and sociological inquiry, stressing its value as a means of reflecting a Zeitgeist and conveying ideas, I tackle the importance of Hesse's novel as a singular example of the genre Bildungsroman, in which the romantic tradition and new kinds of subjectivism converge. I next analyze The Steppenwolf understood as a confession, analysis and manifesto of the outsider artist who constructs his identity against the bourgeois society of his time anticipating the sixties' counterculture.

* Este trabajo forma parte de una línea de investigación que se inscribe en el Proyecto titulado Memoria cultural e identidades fronterizas: entre la construcción narrativa y el giro icónico (Ref.: FFI200805054-C02-01/FISO) que dirige José María González García en el Instituto de Filosofía, CSIC. 
PALABRAS CLAVE:

Sociología de la literatura, Historia cultural, Novela de formación, Crisis fin de siglo, Pesimismo cultural, Romanticismo, El lobo estepario, Herman Hesse.
KEY WORDS:

Sociology of literature, Cultural History,

Bildungsroman, fin-de-siècle crisis,

Kulturpessimismus, Romanticism, The

Steppenwolf, Herman Hesse.

\section{EL VALOR DE LA LITERATURA COMO DOCUMENTO PARA LA CIENCIA SOCIAL}

La sociología de la literatura y del arte surge hace ya bastantes décadas, de la mano de autores tan clásicos como Georg Lukács o Arnold Hauser, y continuadores en la misma línea como Ernst Fischer o Lucien Goldmann, sin olvidar la línea iniciada por la escuela de sociología empírica de la literatura de Burdeos, con Robert Escarpit a la cabeza ${ }^{1}$. Sin embargo, al estar inscritos la mayoría de sus cultivadores en una corriente filosófica y una tradición en ciencia social, la marxista, puesta en tela de juicio por razones tanto científicas como políticas y filosóficas, muchos de estos autores han caído en el olvido o no gozan ya del predicamento y la difusión que tuvieron en otros tiempos. Teniendo en cuenta esto, no está de más volver a plantear lo que ellos ya dieron por supuesto tiempo atrás, esto es, la oportunidad y legitimidad de abordar el estudio de la obra de arte y, en particular, la literaria, desde una perspectiva histórica y sociológica que, partiendo de la premisa de que el contexto sociohistórico determina el proceso de creación de una obra -así como otros procesos relacionados como la difusión, la distribución o la recepción de ésta-, se centre en aquellos aspectos de la misma que mejor desvelen las múltiples conexiones que cabe establecer entre ella y la época y sociedad en la que se inserta.

La obra literaria así concebida pasa a considerarse como un documento para el estudio de asuntos tan importantes para los científicos sociales como acontecimientos y tendencias históricas, movimientos ideológicos o climas intelectuales, incluyendo nociones morales, religiosas o políticas, configuraciones o dinámicas sociales y todo tipo de hechos de la vida social, además de las cuestiones más propiamente literarias como géneros, estilos, escuelas, corrientes artísticas, etc., que tampoco se pueden entender si se separan de su contexto social, al que están estrechamente unidas. Pues de la misma manera que Weber descubrió un vínculo significativo entre la ascética intramundana del protestantismo calvinista y el espíritu capitalista de los primeros empresarios, poniendo en relación ámbitos tan aparentemente distantes como la religión y la economía, se puede igualmente encontrar un nexo de unión entre algunas corrientes artísticas, como el Romanti-

\footnotetext{
1 No menciono aquí a Pierre Bourdieu, el sociólogo más conocido en la disciplina que se ha ocupado de la literatura, porque él no consideraba su obra como una aportación a la sociología de la literatura y el arte, sino como un enfoque teórico global en el que se concede un papel destacado al campo cultural como mecanismo de reproducción social.
} 
cismo, junto con su retoño en la época de cambio de siglo, el Neorromanticismo (en el que puede encuadrarse el autor objeto de estudio), y el Protestantismo, en especial el pietismo, la más intimista y emotiva de las sectas luteranas, a la que el sociólogo Colin Campbell llama la otra ética protestante ${ }^{2}$. Como argumentaré más adelante, establecer esta conexión es imprescindible si se quiere entender la génesis y la dirección espiritual de la sensibilidad reflejada en la novela de Hesse.

Y si toda obra literaria en general puede considerarse relevante como objeto de estudio para la sociología y otras ciencias sociales, también la aparentemente alejada del mundo como es la poesía ${ }^{3}$, la relevancia crece aún más cuando nos centramos en un género específico, la novela, que parece cumplir mejor la función de espejo en el que la sociedad entera se refleja. Especialmente en el caso de la novela realista, salta a la vista que hay en ella una voluntad declarada de reproducir lo más fielmente posible el universo social de la época y el lugar del novelista -o de una época anterior sobre la que éste se documenta, como ocurre con Guerra y paz-y de presentar personajes tipo que puedan ser reconocidos por el lector como tipos sociales (y humanos) reales o, al menos, verosímiles por su similitud con la realidad. Engels había declarado que el Realismo supone la reproducción fiel de caracteres típicos en circunstancias típicas y, aunque puede matizarse la idea de «típico» (para Lukács eran típicos los personajes en el sentido de su significación por expresar las tendencias centrales de una época), sin duda puede aceptarse la definición en términos generales. Aunque la novela realista no pretenda la mera transposición del mundo real al imaginado de la narración, ni se base tampoco estrictamente en el principio aristotélico de la obra artística como mímesis o copia de la realidad - a partir del S. XVIII hay una conciencia clara del papel activo del sujeto en la configuración del mundo y un énfasis en la libertad creativa del autor-, y a pesar de que sea difícil encontrar pautas uniformes para todas las novelas realistas (como dijera Pardo Bazán, «hay cien realismos»`), sí es cierto que, para el Realismo, y de ahí su nombre, la realidad común, la del mundo tal y como es percibido desde la «actitud natural», sin poner en duda su carácter real y compartido intersubjetivamente, es la materia prima con la que construir la novela. La afirmación que hizo Proust según la cual el novelista es como una esponja que debe empaparse de realidad ${ }^{5}$ apunta en esa dirección.

El novelista de esa tradición ha estado embarcado, consiguientemente, en una empresa, la recreación de un mundo social en un contexto histórico, que puede compararse - salvando las distancias de registro- a la empresa sociológica o, incluso, a la histórica, como ilustra el caso de Balzac, que se consideraba a

2 CAMPBELL, Colin, The Romantic Ethic and the Spirit of Modern Consumerism, Oxford, Balckwell, 1989.

${ }^{3}$ Aunque, en ocasiones, como plantea Fischer, el yo lírico se socializa, como ocurre con la poesía de Walt Whitman. Vid. FISCHER, Ernst, El artista y su época, Madrid, Fundamentos, 1972, p. 70.

4 Citado en AMORÓS, Andrés, Introducción a la novela contemporánea, Madrid, Cátedra, 1981, p. 172.

5 Ídem, p. 23 
sí mismo un historiador social ${ }^{6}$. Y es indudable que existe una afinidad, señalada por diversos autores ${ }^{7}$, entre la literatura moderna y la sociología, ya que ambas se han dirigido a propósitos semejantes y se han basado en premisas parecidas sobre la realidad social. Bien es cierto que, como señalara Lukács, el arte siempre ofrece un reflejo individualizante de la realidad, captando lo esencial de la misma a través de lo particular, mientras que la ciencia lo hace de manera generalizante, a través de lo universal ${ }^{8}$, pero aún así, el afán por captar caracteres típicos en situaciones típicas - en la novela con una profundidad psicológica de la que carecen los tipos sociales construidos por el sociólogo - ha estado presente en unos y en otros. $\mathrm{Y}$ hay otros puntos en común que implican una cierta unidad cognitiva y moral que interesa señalar.

Efectivamente, ambas empresas, literaria y científica, han orientado su labor a aumentar la transparencia e inteligibilidad de una sociedad —la moderna - nueva, compleja y difícil de comprender a simple vista, por lo que puede afirmarse que han participado de una misma voluntad de contribuir al autoconocimiento de la naciente sociedad industrial, iluminando con sus investigaciones o con sus obras de ficción zonas poco iluminadas o intentando captar la lógica global, la totalidad ${ }^{9}$. En segundo lugar, ambas formas de conocimiento - pues la literatura también puede considerarse una forma específica de articular un conocimiento sobre el hombre y la sociedad - se han esforzado por encontrar y mostrar los vínculos existentes entre las biografías individuales y las condiciones sociales y acontecimientos históricos que las conforman. Si el sociólogo C. Wright Mills había llamado «imaginación sociológica» a la capacidad para captar la interrelación entre las biografías individuales y la historia, entre el hombre concreto y su sociedad, los problemas personales y los públicos ${ }^{10}$, es indudable que esa imaginación, además de otro tipo de imaginación más propia del fabulador, ha guiado también al novelista en la confección de su obra. La afirmación de Lukács en Problemas del realismo según la cual el gran autor es aquél que consigue revelar los múltiples nexos que unen los rasgos individuales de sus héroes con los problemas generales de su época ${ }^{11}$ pue-

6 Ídem, p. 165.

7 En España, hemos tratado esa afinidad: GONZÁLEZ GARCÍA, José María, La máquina burocrática (Afinidades electivas entre Max Weber y Kafka), Madrid, Visor, 1989 y Las huellas de Fausto, Madrid, Tecnos, 1992; MARTÍNEZ SAHUQUILLO, Irene, «Anomia, extrañamiento y desarraigo en la literatura del Siglo XX: Un análisis sociológico», REIS, № 84, Oct-Dic. 1998, pp. 223-242; y FUSTER GARCÍA, Francisco, «"Afinidades electivas" entre literatura y sociología: El suicidio de Andrés Hurtado» en El árbol de la ciencia como ejemplo de suicidio anómico, EPOS. Revista de Filología, XXV, 2009, pp. 61-75. Fuera de España, el principal autor que ha tratado a fondo la afinidad y relaciones mutuas entre la sociología y la literatura es Wolf Lepenies. Vid. LEPENIES, Wolf, Between Literature and Science: The Rise of Sociology, Cambridge, Cambridge University Press, 1988.

8 Según expone Lukács en Prolegómenos a una estética marxista. Vid. BEDESCHI, Giuseppe, Introducción a Lukács, Buenos Aires, Siglo XXI, 1974, pp. 93-100.

9 Para Lukács, la novela realista, al contrario que la naturalista, que se queda en la superficie, consigue captar y reproducir la totalidad, revelando las contradicciones de una época histórica y una sociedad. Lukács, G.: Problemas del realismo, México, FCE, 1966.

10 MILLS, C. Wright, La imaginación sociológica, México, FCE, 1961.

11 Citado ECO, Umberto, Apocalípticos e integrados, Barcelona, Tusquets, 1995, p. 201. 
de darse por válida y podría aplicarse a grandes novelas como la mencionada Guerra y paz, Rojo y negro, La regenta y un largo etcétera.

Pero es que, además, tanto literatos como sociólogos han centrado su interés en los mismos hechos clave o problemas que, en su época, eran una preocupación si no general, sí al menos compartida por los observadores críticos de la sociedad industrial naciente, con sus nuevos conflictos y lacras; así, unos y otros han analizado o plasmado en sus obras la problemática de la alienación -el principal tema de la novela moderna de acuerdo con los autores marxistas- o la de la anomia, por utilizar una categoría de Durkheim; asimismo han llamado la atención sobre la condición desarraigada del hombre en un mundo que no le proporciona la sensación de «estar en casa» ${ }^{12} ; \mathrm{y}$, por último, han analizado o dramatizado el problema de la «despersonalización» en una sociedad abstracta compuesta de gigantescas estructuras burocráticas en las que el individuo queda aprisionado y a cuya lógica impersonal e inhumana queda sometido, un tema clave en las obras de Weber y Kafka, cuya «afinidad electiva» constituye el tema del libro de José María González García La máquina burocrática ${ }^{13}$. Asimismo, y por continuar con algunas de las coincidencias más llamativas, tanto Weber como Thomas Mann se encargaron de definir el ethos protestante, el primero en La ética protestante y el espíritu del capitalismo y el segundo en Los Buddenbrook, más o menos en la misma época y haciendo, además, el mismo diagnóstico del ocaso de este espíritu. Y, por supuesto, no puede dejarse de señalar que tanto unos como otros se ocuparon de la llamada «cuestión social», esto es, las condiciones miserables en que vivían y trabajaban los miembros de las clases populares, que los novelistas recreaban y denunciaban en obras tan memorables como Oliver Twist, Los miserables o, en el siglo XX, La jungla o Las uvas de la ira, y los sociólogos estudiaban con la misma preocupación moral e intención reformista.

Esa convergencia de la novela clásica y la sociología no es casual: se debe a que ambas bebían de un mismo magma cultural, dominado por el positivismo y el racionalismo, que daba lugar a un tipo de visión epistemológica y del mundo basada en la confianza en la realidad de los hechos, así como en su inteligibilidad, fundada en su sometimiento a un orden regular, como se correspondía con una sociedad, la decimonónica, relativamente próspera y estable, y en la que la burguesía, pese a las amenazas revolucionarias, se sentía segura. Como he explicado en otro lugar ${ }^{14}$, la propia arquitectura de la novela realista típico-ideal, sólida, ordenada, con una lógica lineal, y no sólo la representación del mundo que aparece en ella, expresa esa seguridad y percepción de estabilidad del mundo. Y ese mundo aparece tan fielmente descrito y explorado que la novela de esa tradición

12 El análisis de la literatura de la alienación la abordo en el artículo antes citado: MARTíNEZ SAHUQUILLO, Irene, Op. Cit.

13 GONZÁLEZ GARCÍA, José María, Op. Cit.

14 En un esbozo de la novela realista como tipo ideal. Vid. MARTíNEZ SAHUQUILLO, Irene, La revuelta contra la civilización. D. H. Lawrence y el romanticismo antimoderno, Madrid, CIS, (Siglo XXI de España), 2001, pp. 61-66. 
resulta sumamente útil para reconstruir una sociedad del pasado, como indicara Norbert Elias ${ }^{15}$. Su valor documental para el historiador o el sociólogo interesados en estudiar una época y una sociedad no precisa por ello de una larga argumentación.

\section{LA LITERATURA TESTIMONIAL DE HERMAN HESSE COMO DOCUMENTO DE UNA ÉPOCA HISTÓRICA}

Pero una novela no es sólo una ventana que ofrece una determinada vista del mundo, desde la perspectiva del escritor a su vez condicionada por el contexto histórico y el lugar. Una novela es, también, un testimonio de alguien que, mediante la escritura de la obra, se está explorando, descubriendo, y ofreciendo el resultado de ese autoexamen al público. Lukács entendía la novela, entre otras cosas, como el proceso a través del cual el individuo problemático se conoce a sí mismo, como un proceso de autoconocimiento ${ }^{16}$. Y esa definición es especialmente oportuna cuando se aplica a aquellas novelas que son de carácter testimonial y hasta confesional, y que giran en torno a un personaje central en el que el novelista se proyecta y al que hace vivir sus propias vicisitudes anímicas. En este caso la obra, además de ser un vehículo de expresión de ideas y una forma de ver el mundo, es un documento de carácter testimonial con valor más o menos autobiográfico - aunque no sea propiamente una autobiografía - que puede compararse a otros documentos de ese mismo carácter como diarios, cartas o escritos propiamente autobiográficos, y permite la reconstrucción de una trayectoria vital.

De este modo tenemos acceso, el acceso más directo posible, a una biografía que puede tomarse como típica, no tanto en el sentido estadístico de «normal» o representativa del promedio, como en el sentido que daba Lukács al término, una biografía susceptible de servir como ejemplo ilustrativo de una forma de conciencia y existencia que puede estar emergiendo y acabar propagándose, entre otras cosas porque el público tome como modelo al artista. Efectivamente, si se acepta el diagnóstico del sociólogo Daniel Bell en su obra clásica Las contradicciones culturales del capitalismo, según el cual la cultura ha adquirido una importancia tan preponderante en la sociedad moderna y el artista un lugar tan destacado que «lo que el artista se representa en la imaginación anuncia, aunque sea oscuramente, la realidad social de mañana» ${ }^{17}$, estudiar una obra testimonial de este tipo, como es la de Hermann Hesse que abordaré a continuación, supone asomarse no sólo a una existencia única e inconmensurable, sino a todo un estilo cognitivo y de vida que, con variaciones o desviaciones de distinto grado, se puede encontrar en algunos grupos de la población que, en momentos específicos,

15 ELIAS, Norbert, The Germans. Power Struggles and the Development of Habitus in the Nineteenth and Twentieth Centuries, Cambridge, Polity Press, 1996.

16 LUKÁCS, Georg, Teoría de la novela, Barcelona, Grijalbo, 1975, p. 347.

17 BELL, Daniel, Las contradicciones culturales del capitalismo, Madrid, Alianza, 1977, p. 45. 
pueden considerarla una opción vital, como sucedió en las décadas de los ‘ 50 y '60, cuando Hesse se convirtió en uno de los líderes espirituales de la Generación Beat, primero, y de los hippies y los jóvenes rebeldes de la contracultura, después, especialmente en EE.UU.

A su vez, y aparte del valor señalado que posee la literatura de Hesse como documento testimonial, ésta resulta asimismo extraordinariamente valiosa para sociólogos e historiadores como documento cultural que permite reconstruir el espíritu de una época, ese Zeitgeist marcado por la crisis del que el autor participaba y que estaba intentando plasmar en sus novelas, que son también novelas de ideas. Hasta el propio tipo de novela que escribe el autor que, pese a ser poco innovadora formalmente, se inscribe de lleno en la corriente post-realista de la época, no puede entenderse si no se vincula con el clima general de una época de crisis, la crisis fin-de-siècle, que en Alemania fue especialmente profunda y generó un profundo malestar con la civilización moderna; la dicotomía establecida por muchos intelectuales alemanes entre Kultur y Zivilisation flotaba en un ambiente que se puede calificar de hondamente pesimista, tanto que Kulturpessimismus fue el nombre que recibió y que ha permanecido como etiqueta que se aplica a ese malestar con la civilización ampliamente difundido en las élites culturales germanas. Y no sólo en Alemania, en toda Europa soplaban vientos demoledoramente críticos y de efectos profundamente revolucionarios sobre la forma de ver el mundo. Toda la obra de Hesse, en fin, refleja un clima moral de incertidumbre y zozobra que llevó a ese cuestionamiento radical de todos los supuestos sobre el mundo y la naturaleza humana que habían guiado el pensamiento y la ciencia del siglo anterior y que habían sostenido una novela realista que a los ojos de las nuevas generaciones de escritores había quedado obsoleta y era incapaz de servirles para expresar sus inquietudes y perspectiva frente al mundo. La frase célebre de Virginia Woolf: «Hacia diciembre de 1910 la naturaleza humana cambió» ${ }^{18}$ da idea de hasta qué punto se había propagado la idea de que todo, hasta el propio «hombre», era un concepto revisable. La literatura se hacía eco, además de ese espíritu de crisis, de los hallazgos del psicoanálisis, la filosofía del tiempo bergsoniana o la teoría de la relatividad, entre otros muchos descubrimientos y teorías subversivas e inquietantes.

Todas estas claves se pueden encontrar, en suma, en una obra que se puede estudiar también desde el punto de vista de su recepción —una multitudinaria recepción a juzgar por los millones de volúmenes vendidos-, y el impacto consiguiente que tuvo sobre una población, en su mayoría juvenil, que se sintió atraída por la cosmovisión y el modelo de vida propuestos en ella, y que tal vez se dejó guiar por el programa implícito de autodescubrimiento y autodefinición que el autor proporcionaba. Pero aquí me centraré en el análisis interno de la obra con el fin de ofrecer algunas pistas sobre cómo se puede analizar la literatura del novelista cen-

18 ALLEN, Walter, The English Novel, Harmondsworth, Penguin, 1958, p. 341. 
trando la atención en algunos puntos que me interesan especialmente, como el tipo de novela de formación que cultivó Hesse como vehículo tanto para la articulación de su cosmovisión romántica como para construir su propia identidad de outsider que recrea y explora a través de sus personajes.

\subsection{La Bildungsroman de Hesse en su contexto histórico y en el marco de una filosofía de la vida}

Para poder caracterizar la literatura de Hesse y, en particular, el género que más cultivó, la novela de formación (también escribió poesía, relatos breves y cuentos), hay que entender su continuidad con el pasado, pues Hesse era, más que un innovador o un experimentador (en términos estilísticos), un continuador de toda una tradición en Alemania: la tradición romántica. Su biógrafo Hugo Ball lo definió como el último caballero andante del romanticismo ${ }^{19}$, una definición acertada, si bien matizable, ya que, como dice Theodore Ziolkowski, hay en la obra de Hesse un fuerte elemento existencialista, constatable, entre otras, en El lobo estepa$r i^{20}$. Pero, en todo caso, la sensibilidad romántica junto con algunas preocupaciones características del romanticismo están presentes en toda su obra y sólo Rilke puede comparársele en la época en cuanto a intensidad y pureza de esa sensibilidad. Pero Rilke era poeta y la poesía es el género más apropiado para verter sentimientos y experiencias románticas, desde la unidad con el cosmos hasta el anhelo de plenitud. Hesse, en cambio, era novelista y eligió un género que no se prestaba tanto a la misma tarea de volcar vivencias profundas de un Dichter poco dotado para la observación del mundo social y poco dispuesto a ello, dada la característicamente romántica lejanía al mundo o Weltfremdheit que le caracterizaba.

De hecho, la novela de Hesse está en las antípodas de la novela realista antes esbozada: no es un espejo al mundo exterior, sino al mundo interior. No es una ventana para asomarse a la calle, es una sonda para explorar hondo, en las profundidades de un sujeto ensimismado. Es por ello por lo que se explica que Hesse acudiera, en lugar de a alguna ciencia social, a la psicología profunda de Carl Gustav Jung en busca de inspiración y herramientas para el autoanálisis, que él conocía de primera mano, puesto que se hizo psicoanalizar por el discípulo de Jung, J. B. Lang. Tampoco es de extrañar que eligiera, dentro de la novela, el subgénero que más le permitía explorar una psique y rastrear sus vicisitudes, conflictos y vivencias múltiples, la Bildungsroman o novela de formación, un subgénero con

19 BALL, Hugo, Hermann Hesse, Berlín y Frankfurt a. m., Suhrkamp, 1956, p. 23.

20 Como sostiene el experto en Hesse, Theodore Ziolkowski, Hesse es sobre todo romántico en sus primeras novelas porque fue un admirador del Romanticismo histórico, en especial de su autor preferido, Novalis, pero su obra está en un punto intermedio entre el Romanticismo y el Existencialismo. Vid. ZlOLKOWSKI, Theodore, The Novels of Hermann Hesse. A Study in Theme and Structure, Princeton, N. J., Princeton University Press, 1965, pp. 341-361. 
una raigambre especial en Alemania con Goethe, una de las figuras más reverenciadas por Hesse, como pionero.

La novela de formación se adecuaba al propósito de la literatura de Hesse por dos razones diferentes. En primer lugar, por ser un género moderno, íntimamente ligado al individualismo y a la consiguiente centralidad del yo en la cultura moderna. En segundo lugar, por ser una forma literaria muy ligada a la tradición cultural germánica, de la que Hesse había extraído sus principios tanto artísticos como existenciales. El propio nombre del género, Bildungsroman, hace referencia a un concepto central en la cultura alemana, Bildung, que alude no tanto a una formación práctica para la vida en sociedad como a un autocultivo y desarrollo integral del individuo, en pos de metas como la perfección o la armonía. Como planteara el sociólogo e historiador de la época de Weber, Ernst Troeltsch, Lutero era el prototipo de hombre de la Bildung ${ }^{21}$, volcado como estaba en su propio desarrollo como homo internus y mucho menos interesado en su dimensión social, la del homo externus que se ocupa de las cosas mundanas. Y también consideraba Troeltsch que la Bildungsroman, al mismo tiempo autobiografía y confesión, representaba a la perfección la tendencia alemana a la autoabsorción, a la introspección y el ensimismamiento (Versenkung), que, a su vez, se hallaba íntimamente ligada a la cultura pietista, de la que deriva ese subjetivismo espiritual tan característico ${ }^{22}$. El antropólogo Louis Dumont, que recoge estas consideraciones del sociólogo clásico en sus Ensayos sobre el individualismo, va más allá y sostiene que el intelectual de la Bildung descendiente de Lutero puede ser definido como un individuofuera-del-mundo, que se desentiende de cosas como la política porque ésta no tiene cabida en su concepto de la Bildung, como sostenía Thomas Mann en una conferencia ${ }^{23}$.

El propio Thomas Mann, amigo y admirador de Hesse, pese a las muchas diferencias entre su obra y la de éste, y un representante genuino de esa tradición alemana de la interioridad y de separar tajantemente el reino del arte y de la Kultur del de la política, hizo en su etapa de revisión de su antigua posición expuesta en Consideraciones de un apolítico una caracterización de la Bildungsroman que resulta sumamente reveladora y se ajusta a la perfección a la novela de formación de nuestro autor:

«La característica más fina del típico alemán, la más conocida y halagüeña para su autoestima, es su profunda interioridad. No es ningún accidente que los alemanes dieran al mundo la estimulante intelectualmente y muy humana forma literaria que llamamos Bildungsroman. [....] La interioridad, la «Bildung» de un alemán, implica introspección; una conciencia cultural individualista; la importancia conce-

${ }_{21}$ Como expone Dumont en DUMONT, Louis, Ensayos sobre el individualismo, Madrid, Alianza, 1987, p. 145.

22 lbídem.

${ }^{23}$ Ídem, p. 147. Las palabras de Thomas Mann están contenidas en una conferencia pronunciada algunos años después de su adhesión a la República de Weimar, en Reden und Aufsätze, Berlín, 1965, tomo II, pp. 54-55. 
dida al cuidado esmerado, el modelado, la profundización y perfeccionamiento de la propia personalidad o, en términos religiosos, a la salvación y justificación de la propia vida; un subjetivismo en los asuntos de la mente, por consiguiente, un tipo de cultura que podría denominarse pietista, muy dada a la confesión autobiográfica hondamente personal, en la que el mundo objetivo de la política es rechazado con indiferencia por ser percibido como profano, pues, como dice Lutero, «este orden externo no tiene ninguna importancia» 24 .

La novela de formación de Hesse, en efecto, rezuma ese espíritu que Mann tan bien conocía y que seguía guiando la literatura y el pensamiento de muchas figuras de la época de principios de siglo y entreguerras, especialmente la de aquellos más imbuidos de pesimismo cultural y más críticos de la civilización científico-técnica y de la sociedad de masas que veían como una amenaza a esos valores espirituales que defendían. Hay que entender que Hesse, además de decantarse por la Bildungsroman como forma literaria propia para dar forma a sus inquietudes y sus historias en gran parte autobiográficas, seleccionó aquélla que era más afín a su concepción de la Bildung: la más romántica y extramundana. Es importante esta precisión porque en la obra de Goethe, el fundador de este género, se encuentran dos modalidades de novela de formación. Un primer modelo, que se corresponde con su etapa romántica — la del Werther-y da lugar a Los años de aprendizaje de Wilhelm Meister, plantea la formación como un proceso de autodespliegue del individuo desde dentro, entendiendo a cada individuo como una mónada leibniziana y como microcosmos que contiene el mundo en su totalidad, como explica José $\mathrm{M}$. González García ${ }^{25}$. La segunda forma que adopta la Bildungsroman en Goethe, coincidiendo con su última época, más mundana y burguesa, tiene como ejemplo más reconocible Los años de andanzas de Wilhelm Meister y plantea la formación de una manera menos fáustica, ya que el joven debe renunciar a la personalidad total en aras a la adaptación a la sociedad y a la autorrealización a través de una profesión: el Kulturmensch da paso, como señala González García, al Fachmensch, al hombre especializado que ocupa su lugar en la sociedad burguesa ${ }^{26}$.

Pues bien, el héroe de la novela de formación de Hesse es, decididamente, el Kulturmensch de la tradición romántica y luterana, un héroe de la resistencia, en guerra con el mundo - como Sinclair, el héroe de Demian, todos ellos están im Streit mit der Welt ${ }^{27}$ - que se niega a adaptarse al entorno, entiende su crecimiento personal como un asunto puramente interno y se dirige a metas tan poco mundanas como «llegar a ser un santo», como se lee en Demian, o vivir todo aquello que quisiera brotar de él (aus mir heraus wollte) ${ }^{28}$. Hesse funde, así, la tra-

24 Escrito de 1923, citado por SWALES, Martin, The German Bildungsroman from Wieland to Hesse, Princeton, N. J., Princeton University Press, 1978, p. 159 [la traducción es mía].

25 GONZÁLEZ GARCÍA, José María, Las huellas de Fausto..., p. 96.

26 Ídem, p. 97.

27 HESSE, Hermann, Demian, Frankfurt, Suhrkamp, 1974, p. 77.

28 ĺdem, p. 81 y 96.

29 ARGULLOL, Rafael, El héroe y el único. El espíritu trágico del romanticismo, Madrid, Taurus, 1982, p. 34. 
dición que nace con Goethe con lo más romantisch —término usado por Jean Paul para designar la nueva sensibilidad ${ }^{29}$ — del movimiento romántico, con el cual se identificaba planamente. Si el romántico, como el Empédocles de Hölderlin, era un «enemigo mortal de toda existencia unilateral» e inclinado, por temperamento y filosofía, a odiar la civilización ${ }^{30}$, Hesse, quien también participaba de la admiración por el «profeta de la unidad» que, como explica Peter Gay, se extendió en el periodo de Weimar ${ }^{31}$, siguió la misma senda y, en pos del mismo ideal de hombre integral y plenamente realizado, decidió mantenerse al margen de la civilización y sociedad modernas que hacían imposible una vida regida por ese ideal. De ahí que sus héroes, los protagonistas de sus novelas y alter egos del autor, vivan hacia adentro, apartados del mundo, y siempre ocupándose de sí mismos; como dice Sinclair en Demian:

«Siempre estaba ocupado conmigo mismo, siempre conmigo mismo (Ich war immer mit mir selbst beschäftigt, immer mit mir selbst)»32

El individualismo de Hesse es, así pues, un individualismo muy distinto del que describe Weber en La ética protestante y el espíritu del capitalismo, el capitalismo burgués de Franklin o, en literatura, de Daniel Defoe. El suyo es del tipo que Robert N. Bellah llama «expresivo» en oposición al «utilitario», esto es, a aquel ligado aún a la ética del trabajo ${ }^{33}$. Si el burgués prototípico se realizaba en la profesión y se medía con arreglo al baremo de los logros obtenidos, el héroe de Hesse, un antiburgués confeso, no aspira a validarse mediante obras, como tampoco ha de pasar pruebas de competencia social; en todo caso, se somete a pruebas heroicas de superación espiritual pero, sobre todo, lo que busca no está en el exterior, sino en el interior: se busca a sí mismo, está en peregrinaje perpetuo hacia el propio yo y aspira a comprender y expresar aquello que va encontrando mientras ausculta su alma. De hecho, el programa que se desprende de sus novelas de formación tiene mucho en común con el que planteaba Rousseau, un programa de «regreso a sí mismo", como lo define Marshall Berman en The Politics of Authenticity ${ }^{34}$, en busca de la luz y de la autenticidad que es imposible encontrar en la sociedad, ya que ésta impone máscaras —o cubre con velos (otra metáfora cara a Rousseau) que impiden conocer a los otros y alienan al individuo de su verdadero ser. Por supuesto, para superar esa autoalienación que es, para Rousseau, consustancial a la vida social, es necesario apartarse del teatro social, despojarse de la máscara o el velo, y dedicarse ya al autocultivo, ya al cultivo de relaciones humanas que no estén desvirtuadas por su sometimiento a reglas o moldes sociales.

30 GAY, Peter, La cultura de Weimar. La inclusión de lo excluido, Barcelona, Argos-Bergara, 1984, p. 70.

31 Ídem, p. 69.

32 Ídem, p. 97.

33 BELLAH, Robert N. et alii, Hábitos del corazón, Madrid, Alianza, 1989.

34 BERMAN, Marshall, The Politics of Authenticity. Radical Individualism and the Emergence of Modern Society, N. Y., Atheneum, 1972, p. 82. 
Otra de las ideas centrales de Hesse, sacada de Jung, una de las figuras de la época que más le influyó, es que el hombre lleva en su seno el Urwelt o mundo primigenio (que reside en el inconsciente), que el núcleo de su yo refleja el macrocosmos, y que en la ontogénesis se van repitiendo las etapas de la filogénesis, de manera que el desarrollo de cada ser humano reproduce el de la humanidad. A esta idea capital hay que añadir la creencia cristiana de que cada individuo carga con la inmensa culpa por los males del mundo que ha de expiar, así como la concepción extraída de la filosofía hindú que tanto le marcó de que no hay un yo, sino una multiplicidad de yoes, de que la persona es un ovillo de personas, y que "como cuerpo cada hombre es uno, como alma nunca" 35 , como se lee en El lobo estepario. Y, por último, Hesse, discípulo devoto de Nietzsche, comparte la misma visión aristocrática de la existencia y la humanidad y, en consonancia con ella, predica una religión de virtuosos, por utilizar la expresión de Weber, que sólo unos pocos, los elegidos, pueden practicar; esto es, aquellos que se distinguen por mantenerse apartados del rebaño - Herde es una palabra que aparece reiteradamente en su obra, como en la de Nietzsche-, así como por el sufrimiento, concebido como un signo de distinción. La frase del filósofo «lo que define la jerarquía es la profundidad con que uno puede sufrir» ${ }^{36}$ resume a la perfección una convicción que también hacía suya Hesse.

Estos son los mimbres, muy resumidamente, con los que Hesse confeccionó una Bildungsroman intimista, teñida de sentimientos románticos y repleta también de reflexiones y meditaciones sobre la vida, ya que a la literatura del novelista se le puede aplicar la categoría que usó Lukács para referirse a gran parte de la literatura de la Alemania del momento, Weltanschauungsliteratur ${ }^{37}$, esto es, literatura filosófica portadora de una cosmovisión. Y todas las novelas de formación que escribió a lo largo de toda su vida siguen el mismo esquema, un esquema sencillo, con elementos procedentes de los cuentos populares, como que los héroes tengan que enfrentarse a pruebas dolorosas para llegar a su meta, en este caso, la autorrealización, y plantean el mismo programa de «redención», si no estrictamente religioso, sí, al menos, con implicaciones religiosas.

Muy brevemente, y por centrar la atención en el argumento, todas ellas giran en torno a un individuo problemático, no sólo problemático, en crisis, normalmente adolescente — salvo el caso peculiar de Harry Haller, el lobo estepario-, introvertido, singular e inadaptado que está construyéndose una identidad de espaldas a la sociedad circundante, de la cual se autoexcluye. Se autoexcluye de antemano porque establece una distancia insalvable entre sí mismo y los demás, con los que no es capaz de intimar ni encontrar afinidad alguna porque son seres superficiales y falsos que no son capaces de desprenderse de sus máscaras. Así, ya en su se-

\footnotetext{
35 HESSE, Hermann, Der Steppenwolf..., p. 66.

36 MANN, Thomas, Schopenhauer, Nietzsche, Freud, Barcelona, Plaza \& Janés, 1986, p. 131.

37 Lo dice en El asalto a la razón, citado en FORMAN, Paul, Cultura en Weimar, causalidad y teoría cuántica, 1918-1927, Madrid, Alianza, 1984, p. 52.
} 
gunda novela, Peter Camenzind, el autor plantea la contraposición entre el ser aparte que es el muchacho protagonista, el primer representante de outsider, y el resto:

«La mayoría de ellos tenían la misma forma estereotipada de homo socialis, y todos me daban la impresión de estar emparentados, en virtud de un espíritu sociable y nivelador del que yo únicamente carecía»38

Se trata de la misma contraposición que establece Ortega entre el hombremasa y el hombre selecto o, volviendo a Nietzsche, entre los hombres hiperbóreos y la masa o el rebaño. En el caso de Hesse, está latiendo, asimismo, la diferenciación psicológica que establecía Jung entre hombres extrovertidos y hombres introvertidos, con los cuales, naturalmente se identificaban tanto Jung como Hesse. Pero lo que interesa destacar aquí es la consecuencia de ese foso que separa a dos tipos de hombres radicalmente opuestos y sin posibilidad de comunicación: ésta es que el joven cuyo desarrollo espiritual se relata está condenado a la soledad, a llevar todo el peso de su formación sobre sus hombros, a no contar con la ayuda de sus congéneres, con la salvedad de aquellos distinguidos por las mismas características especiales, dotados de un sexto sentido, y poseedores de algún saber esotérico que son capaces de comunicar al neófito, como Demian hace con Emil Sinclair. Las únicas relaciones significativa que aparecen en las novelas de desarrollo de Hesse son, así, las que establece el protagonista (masculino) con el maestro o los maestros iniciáticos y la que le une a alguna mujer que representa a la mujer-madre o la mujer-naturaleza capaz de ayudar al hombre a encontrarse y facilitarle, también, una vía para la anhelada unio mystica.

Salvo esos vínculos excepcionales, el protagonista está, empero, solo en el mundo y abandonado a sus propios recursos. Porque otro de los elementos comunes en las novelas de Hesse es que las instituciones educativas y el mundo adulto en general, en particular el burgués, que es al que los personajes pertenecen, no proporcionan ninguna enseñanza que pueda enriquecer o ser útil al joven que se está formando intelectual y sentimentalmente. Son, por ello, más que novelas de formación, novelas de autoformación o autoaprendizaje (Selbsterziehung), en las que el educando está, como estuvo Hesse en su juventud, abocado a aprender de forma autodidacta, así como a chocar constantemente con las instituciones escolares, que no salen muy bien paradas en ellas. Esta cuestión tan destacada lleva al biógrafo y amigo de Hesse mencionado, Hugo Ball, a atribuir al rígido y anticuado sistema educativo alemán tanto la proliferación del género -en ningún país, explica, hay tantas novelas de aprendizaje como en Alemaniacomo la profusión de escritores autodidactas ${ }^{39}$.

${ }^{38}$ HESSE, Hermann, Peter Camenzind, Berlín, Suhrkamp, 1974, p. 84 [la traducción es mía].

39 BALL, Hugo, Op. Cit., p. 73. 
Sin embargo, lo que aquí me interesa resaltar no es tanto esa crítica a la educación formal y a los entornos escolares de ese momento histórico que asoma en sus obras (tampoco salen reflejados con luz más favorable en la novela de formación de Robert Musil Las tribulaciones del joven Törless) como la propia concepción que Hesse tiene sobre la formación (Bildung), así como sobre las condiciones favorables que la propician. Pues bien, como sucede que, para el autor, la educación no es fundamentalmente un proceso de adquisición de conocimientos o habilidades (de un homo sapiens o un homo faber orientado al dominio del entorno), sino un desarrollo espiritual cuya finalidad es encontrar sentido y experimentar plenitud (metas más propias del homo religiosus), no se trata tanto de encontrar algún entorno institucional que pueda promoverla (sea la escuela u otro distinto) como de favorecer las condiciones interiores, espirituales, que ese desarrollo requiere. $Y$ esas condiciones son la apertura, la receptividad y la disposición a transformarse constantemente, a metamorfosearse en las distintas naturalezas potenciales que alberga cada uno en su interior. Comoquiera que la adolescencia es la fase de mayor apertura, experimentación y búsqueda, así como aquella en la que todavía no ha fraguado una personalidad definitiva, esta etapa es la preferida por Hesse, como demuestra el hecho de que la gran mayoría de sus protagonistas sean adolescentes. Pero a su vez, lo que plantea el autor, que no quiere resignarse a que esa configuración psicológica idónea para la búsqueda y el autodespliegue se pierda en la edad adulta, es que aquélla se convierta en permanente, en un modo de vida, en una actitud vital duradera. Dado que su modelo de hombre es el peregrino, el buscador, el que está siempre en camino a sí mismo, siempre buscándose pero sabiendo que el proceso de «llegar a ser», de devenir (werden), es más importante que el "ser» ${ }^{40}$, y que la indeterminación es preferible a estar atado a un forma fija, esa orientación vital que se suele asociar a la adolescencia o juventud es la única que puede convenir al héroe de Hesse, que no aspira a las metas habituales de estabilizarse o «sentar la cabeza» además de afianzarse en una profesión. Por ello Hesse deja ver la dimensión productiva y enriquecedora que tienen las crisis que sufren todos sus personajes y que les coloca al borde del suicidio (como estuvo él en distintas épocas), pues una crisis es una oportunidad para el desarrollo personal y el descubrimiento de nuevos caminos que ensanchen el horizonte vital. También la crisis de un hombre maduro, como es Harry Haller, el protagonista de El lobo estepario, es entendida como una etapa crucial de experimentación vital que permite al héroe crecer espiritualmente, que es de lo que se trata. Pero esta novela requiere un tratamiento aparte.

\subsection{El lobo estepario como testimonio, análisis y manifiesto del outsider}

Se puede considerar al El lobo estepario como una obra cumbre entre las novelas de formación de Hesse, una obra de 1927, escrita en la madurez del artista,

40 Como indica Juan Antonio Roche en relación con el arte romántico. ROCHE CÁRCEL, Juan Antonio, La sociedad evanescente, Barcelona, Anthropos, 2009, p. 87. 
que contaba con cincuenta años, y que da testimonio de la crisis que sufrió a esa edad a través de un personaje, Harry Haller, el lobo estepario, en el que el autor se proyecta. Sin embargo, a pesar de ser una de las obras de más claro contenido confesional —un autoanálisis en toda regla—, está concebida como un documento de la época, que es como la presenta el editor del manuscrito de Harry Haller (encontrado en la pensión donde éste se hospedaba) y que ofrece al lector. Efectivamente, el prologuista justifica el valor de los apuntes editados por él argumentando que la chifladura de Harry Haller no es la de un solo individuo, sino la enfermedad de una época, una época de transición en la que está atrapado el protagonista, y que afecta especialmente a los miembros más espirituales, con más talento, de la sociedad ${ }^{41}$. Las anotaciones de Harry Haller son, así, presentadas al lector como el testimonio de una crisis personal ligada a la crisis general de una época y que, por ello, resultan valiosas, además del valor que puedan poseer como guía espiritual para los que se hallan desorientados. Estos últimos, deja claro el libro, han de formar parte de un grupo selecto de espíritus afines: de ahí que las anotaciones de Harry Haller lleven como encabezamiento la frase «sólo para locos", al igual que la parte titulada Tratado (Tractat) que interrumpe las anotaciones, y que a la entrada del teatro mágico Harry adivine la advertencia «no para cualquiera».

Con una estructura más compleja que la de otras novelas de formación anteriores -el estudioso de Hesse antes citado, Theodore Ziolkowski, la califica de una sonata en prosa ${ }^{42}$-, Hesse ofrece en la obra, así, mucho más que una historia: brinda todo un diagnóstico de la crisis espiritual de la época, un psicoanálisis de un individuo en crisis que ejemplifica la enfermedad del momento - como lo hace Hans Castorp, en La montaña mágica, la novela de formación escrita por Mann pocos años antes-, una filosofía que pretende a la vez explicar la enfermedad y señalar la cura, y hasta un análisis crítico de ese tipo psicológico cuya radiografía se ofrece y cuyos rasgos son, claramente, los del autor. Precisamente porque es un libro muy complejo y que permite muchas lecturas y niveles de análisis no fue muy bien entendido, además de que causó escándalo (o entusiasmo, como el de Timothy Leary y otras figuras de la contracultura, que lo acogieron por lo que ellos entendían como celebración de la experiencia psicodéli$\mathrm{ca}^{43}$ ), y el novelista tuvo que salir en su defensa aclarando algunos malentendidos. Naturalmente, aquí no se trata de interpretar toda la obra, una de las más ambiciosas de Hesse junto con El juego de los abalorios, entre otras cosas, porque una obra de este tipo no tiene una sola interpretación (esa que Susan Sontag llamaba irónicamente «la venganza del intelecto contra el arte» ${ }^{44}$ ), sino de centrar la aten-

41 HESSE, Hermann, Der Steppenwolf..., p. 27.

42 ZIOLKOWSKI, Theodore, «Hermann Hesse's Steppenwolf: A Sonata in Prose», en LIEBMAN, Judith (ed.), Hermann Hesse. A Collection of Criticism, New York, Mc.Graw-Hill, 1977, pp. 91-109.

${ }^{43}$ MAYER, Sigfrid, "Die Hesse-Rezeption in den Vereinigten Staaten», Text und Kritik, 10-11, Julio 1983, pp. 87-88.

${ }_{44}^{4}$ SONTAG, Susan, Against Interpretation and Other Essays, Londres, N. Y., Penguin, 2009, p. 7. 
ción en aquellos puntos de la novela que más revelan las intenciones centrales del autor, a la vez que con más claridad permitan reconstruir el tipo de identidad que Hesse, a través de su alter ego (que no por casualidad tiene un nombre y apellido con las mismas iniciales que los del escritor), estaba construyendo y ofreciendo al lector como modelo.

Lo primero que conviene señalar es que la obra no supone una ruptura con las anteriores, pese a que formalmente sea más innovadora. Sigue siendo básicamente la misma Bildungsroman que, una vez más, relata el difícil y doloroso desarrollo espiritual de un personaje masculino con los mismos rasgos psicológicos que sus predecesores: introvertido, neurótico, inadaptado, nostálgico, hipocondríaco, melancólico y atormentado, aparte de ser caracterizado sociológicamente como un burgués renegado y crítico de su clase social, pero incapaz de abandonar del todo sus hábitos burgueses. Y como en las otras novelas, la parte más extensa (la segunda) relata su proceso de aprendizaje, al modo del de Wilhelm Meister en Los años de aprendizaje, al que se concede un aire de inevitabilidad, puesto que el motivo del destino, como en la obra de Goethe, guía el relato, como indica Ziolkowski ${ }^{45}$. En lo que sí es diferente a otros héroes de Hesse es que es de edad madura (tiene cuarenta y ocho años), además de que lleva un apodo revelador - el lobo estepario- que, cual animal totémico, es el emblema de la especie a la que pertenece o con la que él mismo se siente hermanado. El lobo era un animal que siempre había atraído al escritor y en la etapa en la que vivió en Gaienhofen, retirado del mundanal ruido, y dando sus primeros pasos de escritor, ya había escrito un relato titulado Der Wolf en el que surgía el motivo del lobo - que representa lo indómito y es contrapuesto a la civilización ${ }^{46}$ - que retomaría en El lobo estepario. Y sin duda, la imagen del lobo estepario resultaba muy adecuada para representar a ese outsider que se automargina de la sociedad burguesa -aunque sin dejar de ser el individualista pequeñoburgués que es por naturaleza-, que rechaza la adocenada y falsa vida en sociedad y que sólo se junta con seres como él, marginales y poco convencionales, hasta el punto de ensayar formas de vida alternativas, que incluyen sexo, drogas y jazz. Asimismo, el lobo es, por naturaleza solitario, un animal antitético a cualquier especie gregaria y con él Hesse podía identificarse tanto por su carácter difícil, retraído y obstinado (Eigensinn es, para Ball, otra de las características de Hesse), como por su rechazo a la multitud gregaria a la que, como Nietzsche, suele denominar con la palabra rebaño (Herde) y que es una de las dianas de su crítica a la civilización moderna.

Así pues, el héroe de la novela es el mismo que en otras pero, si cabe, más radical en su postura antisocial y, además, mucho más autoconsciente, ya que está dispuesto a desmenuzar su propia psique y a compartir el análisis lúcido y, en oca-

${ }^{45}$ ZIOLKOWSKI, Theodore, op. cit., p. 100.

46 BALL, Hugo, op. cit., p. 118. 
siones autocrítico, con el lector. Por ello el libro resulta tan interesante como documento, entre otras cosas, para estudiar a un tipo psicológico y social que está perfectamente retratado y estudiado. En efecto, por un lado El lobo estepario puede tomarse como una confesión en la que el autor se desnuda por completo. Pero, por otro, no es sólo un testimonio confesional ni puede leerse exclusivamente como un relato autobiográfico, ya que en esta novela, en mucha mayor medida que otras, Hesse se distancia de su alter ego adoptando distintos roles: el del psicólogo que bucea en las profundidades de la psique del protagonista; el del sociólogo que intenta ligar la enfermedad del paciente con la de la época y con la clase social y tipo de educación recibida; el del filósofo existencialista que medita sobre el sentido de la vida y de la muerte - aunque, al contrario que los existencialistas, Hesse no se regodea en el absurdo-; el de líder espiritual que busca y encuentra algún sentido a la vida y señala un camino de salvación; $y$, por último, hasta el del crítico que le hace ver al paciente sus flaquezas y contradicciones.

Sin embargo, y pese a la distancia analítica que Hesse establece con el personaje, como si él mismo se estuviera desdoblando en psicoanalista y paciente, la novela es, claramente - y así fue entendido por su público-, una celebración de la figura del outsider que tan a fondo se examina. Por eso, Harry Haller, por muy objeto de análisis que sea, sigue siendo un héroe romántico con el que el lector puede identificarse y tomar como ejemplo. Y la forma de vida que ensaya para encontrar un salida a la crisis, bohemia, marginal, intensamente dedicada a experimentar nuevas formas de conciencia y existencia, que, al final, conducirán al protagonista a la liberación a través de una vida alternativa a la burguesa, fue entendida por muchos como una glorificación de formas de vida contraculturales, como las que practicaban, en su época, los jóvenes Wandervogel u otros grupos unificados bajo el lema Zurück zur Natur's (regreso a la naturaleza) —un lema que a Hesse le parecía simplificador, como dice en un episodio de la novela - o las que practicarían, después, los hippies y otros jóvenes de las distintas olas contraculturales que barrieron EE.UU. y Europa en los ' 50 y ' 60 , los cuales siguieron el ejemplo de Hesse y convirtieron sus libros en libros de culto, entre ellos, El lobo estepario.

Pero Hesse no pretendía únicamente una vuelta a la naturaleza, o no era lo fundamental. Su lema era más bien ese regreso a sí mismo al que antes me he referido. Y el camino era, claramente, un camino hacia el interior, un Weg nach innnen, más que hacia algún lugar localizable en el mapa. Aunque gran parte de su vida viviera retirado en el campo, como eremita que era, y pese a que en sus novelas haya un cántico a la naturaleza y a la vida sencilla y una nostalgia de la $\mathrm{Ge}$ meinshaft rural (la misma que empuja a Peter Camenzind a volver a su pueblo natal tras su peregrinaje por el mundo), en El lobo estepario el autor hace vivir al protagonista todo el periplo existencial en una ciudad y Pablo, su maestro iniciático, es un músico de jazz que hace una vida característicamente urbana. Todas las experiencias que vive el héroe en el círculo bohemio en el que se integra son típicas de un ambiente cultural urbano. Por supuesto, en esta novela, como en otras, 
hay toda una crítica demoledora de la civilización industrial, ejemplificada por la máquina -en uno de los sueños del protagonista, éste se dedica a disparar contra los odiosos coches que transitan por la carretera-y, cómo no, por la ciudad. Pero ello no impide que el héroe haga uso de las ventajas que la ciudad le brinda, por ejemplo, esos ambientes bohemios antiburgueses, para perseguir su meta que, al ser de carácter interno, podía perseguirse en cualquier lugar.

Muy resumidamente, la meta consiste en reconciliar en sí mismo las dos naturalezas que le desgarran en dos mitades y le producen una esquizofrenia que el autor-personaje, además de diagnosticar, reivindica (ya que, como la crisis que padece, es un estímulo para la transformación interna y el despliegue de sus distintos yoes). Naturalmente, esas dos naturalezas o principios en lucha son definidas y analizadas en la obra; así, si una es la identificada con el espíritu, así como con el burgués que habita en su interior, la otra, la más reprimida, está asociada a la naturaleza y a la sensualidad (es el lobo que lleva dentro), así como a las clases populares. La superación de ese desgarro que atormenta a Harry Haller —como a la mayoría de los personajes de Hesse - es, por tanto, el objetivo principal al que se dirige su aprendizaje iniciático, que culminará con su iniciación sexual a cargo de Hermine, primero (cuyo nombre no por casualidad es la feminización del autor), y María, después, así como su iniciación en las drogas y la música de jazz a cargo de Pablo, el saxofonista, y la entrada en el teatro mágico donde, por fin, dará el salto que le conduzca a la sabiduría, que exige también desarrollar un sentido del humor del que carece por completo el protagonista.

Pero aquí no me interesa tanto analizar la secuencia del proceso de iniciación como su sentido y el papel que juega en la configuración de una identidad de outsider - de Aussenseiter, dicho en el idioma de Hesse- que es el foco de interés en este artículo. Pues bien, tal y como se ha dicho antes, el autor, que sigue las huellas de Rousseau en su concepción de la sociedad como agencia desnaturalizadora y corruptora del hombre, entiende el proceso iniciático que ha de seguir el héroe para reconstituir su yo auténtico como un proceso de desconstrucción de la propia personalidad (que hay que desmontar con sus racionalizaciones), de desinhibición y de liberación dirigidos a trasladar al iniciado a una dimensión más allá del espacio (en especial, del espacio social) y del tiempo que le permita entrar en contacto con las fuerzas eternas que mueven el mundo. En efecto, el autor plantea la iniciación como un portentoso ensayo de des-socialización, en consonancia con la idea profundamente negativa de sociedad como un espacio profano y desencantador ( o des-sacralizador) por antonomasia en el que ni el homo aestheticus ni el homo religiosus que habitan en sus personajes pueden encontrar acomodo, ni tampoco tener lugar la transfiguración ansiada. Porque a lo que aspira Hesse, en coherencia con su filosofía sincrética que funde elementos del cristianismo y el budismo, es a una unio mystica que re-ligue al hombre con la naturaleza y que, unida a una liberación de las inhibiciones que refrenan sus impulsos, le permita reencontrase consigo mismo, integrando asimismo esa dimensión espiritual que la materialista civilización moderna también tiende a ahogar y a negar. Se 
trata de todo un programa diseñado para ese individuo-fuera-del mundo, por utilizar la expresión de Dumont, que se sitúa en otro plano, pues su reino no es de este mundo, para perseguir sus propias metas, desentendiéndose de todo aquello que le distraiga de su concentrada y concéntrica búsqueda de sí mismo.

Como es natural, tal concepción del desarrollo o formación de la personalidad del individuo no puede sino conducir a una radical y absoluta secesión de éste respecto a la sociedad circundante. El Aussenseiter que construye el autor, en este caso el atormentado Harry Haller, no es por tanto más que una consecuencia lógica de esa filosofía. Pero, además, el escritor hace de necesidad virtud y glorifica a esa figura que presenta adornada de cualidades excelsas. Así, como en otras novelas, el protagonista de El lobo estepario está dotado de una naturaleza singular, que lo eleva por encima de los demás mortales; además de ser fuerte y salvaje, como el lobo, tiene disposiciones geniales, un alma de artista, y una espiritualidad elevada que le hermana con todos aquellos que pertenecen a la categoría que Hesse llama «los hombres espirituales» (die Geistigen), y que hace también referencia al pueblo alemán, un pueblo musical que prefiere la música a la palabra ${ }^{47}$. Y como la novela está salpicada de consideraciones críticas, Hesse ofrece a la vez una definición y diagnóstico crítico de una de las disposiciones centrales de su personaje, ligada a la cultura alemana:

«Todos nosotros, seres espirituales, no nos sentíamos en casa en la realidad, nos sentíamos ajenos a ella y le éramos hostiles, por eso jugaba un papel tan miserable el espíritu en nuestra realidad alemana, en nuestra historia, en nuestra política, en nuestra opinión pública» ${ }^{48}$.

Aquí aparece la primera clave que nos permite entender la separación radical que Hesse sentía con respecto a la sociedad de su tiempo y, en particular, la alemana, que motivó su permanente residencia en Suiza además del hecho significativo de que, en lugar de seguir el ejemplo de su amigo Thomas Mann comprometiéndose con la República de Weimar, se mantuviera al margen e, incluso, dimitiera de la Academia Prusiana de las Artes para la que había salido elegido en $1926^{49}$. Además de que ya se hubiera distanciado del país —una de sus dos patrias - como consecuencia del nacionalismo desatado durante la guerra, que le repelía (como le repelió el naciente nacionalsocialismo), ese retraimiento se puede explicar por razones más estructurales que tienen que ver con la disposición u orientación espiritual. Pues, como se desprende claramente de las líneas antes citadas, el autor se contaba entre aquellos que estaban sufriendo esa «pérdida de realidad» que, de acuerdo con Ernst Fischer, había comenzado con los románticos y que se había convertido en el siglo XX en un problema fundamental ${ }^{50}$. La alie-

47 HESSE, Hermann, Der Steppenwolf..., p. 148.

48 Ídem, p. 149.

49 MICHELS, Volker, Hermann Hesse. Sein Leben in Bildern und Texten, Frankfurt a. m., Suhrkamp, 1979, p. 230.

50 FISCHER, Ernst, El artista y su época..., p. 18. 
nación del artista de la realidad, que desde su perspectiva subjetiva no es real (esto es, que carece de significación), era una experiencia bastante extendida. En el caso particular de Hesse, esa pérdida de la realidad era especialmente intensa y persistente dada la orientación weltfremd o ajena al mundo en la que había sido educado, esto es, en un entorno familiar pietista integrado por pastores y misioneros que seguía consiguientemente la tradición luterana antes descrita.

Pero, volviendo a la novela, y al personaje en el que el autor vuelca sus vivencias, si Harry Haller, como buen lobo estepario, no puede sentirse a sus anchas en ningún tipo de sociedad, pues su naturaleza indómita le empuja a separarse del rebaño, menos aún puede sentirse en casa en una sociedad, la moderna, que, como indican Berger, Berger y Kellner, provoca más que ninguna otra, debido a sus rasgos estructurales, ese fenómeno que denominan homelessness ${ }^{51}$ en su clásica obra Un mundo sin hogar y que, según su diagnostico, afecta a cada vez más individuos. Especialmente a aquellos que, como Hesse, necesitan otorgar un sentido de carácter religioso al entorno y resienten la secularización que ha transformado el mundo social en un erial para el espíritu. No se puede olvidar que Harry Haller, como otros protagonistas de Hesse, es, ante todo, un buscador de sentido, transido del anhelo de «dotar de un nuevo sentido una vida humana que se ha vuelto absurda (sinnlos)» ${ }^{52}$, como se lee en las primeras páginas de las anotaciones de Harry Haller. De ahí que el entorno industrial, urbano, y burgués de la sociedad del momento le produzca la siguiente vivencia:

¡Oh, es difícil encontrar la huella de Dios en medio de esta vida que llevamos, en medio de esta época tan satisfecha, tan burguesa y falta de espiritualidad, a la vista de esta arquitectura, de estos negocios, de esta política, de estos hombres! ${ }^{153}$

Al igual que el poeta T. S. Eliot, Hesse veía, en fin, una «tierra baldía» a su alrededor con la que no podía identificarse. Pero es que también se sentía enajenado de la clase en la que él había nacido, crecido y en cuyos valores había sido educado. Unos valores, los burgueses, que repudiaba porque reprimían toda una parte de su ser, la parte sensual, instintiva, que el Cristianismo había condenado. La vieja moral judeocristiana basada en la dualidad bien y mal, dios y diablo, era para él, como para Nietzsche y Dostoievski, una moral estrecha y resentida que había que superar. En sí mismo había dejado como herencia una escisión dolorosa que le había atormentado toda la vida y quería buscar una filosofía y una forma de existencia que le permitiera, como se ha dicho antes, reconciliarse con la dimensión prohibida. En Demian, la filosofía era la del Dios Abraxas, que reúne en su seno el bien y el mal. En El lobo estepario Hesse empuja a su alter ego a liberarse en un plano más terrenal, aunque deja ver que la moral burguesa todavía ata

51 Vid. BERGER, Peter L., BERGER, Brigitte, y KELLNER, Hansfried, Un mundo sin hogar. Modernización y conciencia, Santander, Sal Terrae, 1979.

52 HESSE, Hermann, Der Steppenwolf..., p. 32.

53 Ídem, p. 35. 
a Harry Haller cuando se niega a participar en una orgía de a tres que le propone Pablo. En cualquier caso, y pese a sus contradicciones, Harry se convierte en un renegado de su clase y de la forma de vida acomodaticia, biedermeier, propia de su grupo de origen y prefiere la compañía de los bohemios o de mujeres sencillas y sin ilustración, como María, que le ponen en contacto con las fuerzas elementales de la vida.

No obstante, y en contra de algunas interpretaciones populares que se hayan podido difundir sobre su obra (una obra tan popular que hasta existe un grupo de música pop que ha adoptado el nombre Steppenwolf), el autor no presenta a su personaje con rasgos puramente rebeldes: no es ni un antihéroe ni un rebelde sin causa. Es un héroe que, si se ha convertido en un outsider o un renegado, ello es debido a su naturaleza superior al mismo tiempo que porque lo que busca no se halla en su entorno. Su búsqueda de sentido y de identidad es mostrada, así, como una búsqueda heroica, entre otras cosas, porque supone luchar contra los elementos y aceptar el sufrimiento; un sufrimiento causado tanto por la soledad y el aislamiento al que se ve abocado como por la culpa inmensa que le atormenta, una culpa inespecífica, que ha de purgar. De esta manera, el outsider que lucha contra el mundo y que se repliega orgullosamente en su yo se ve investido de una heroicidad trágica, que reivindica y convierte en una de sus señas de identidad. É no está destinado a la felicidad, a la cómoda felicidad burguesa, que desprecia: su destino es sufrir porque lo que desea sólo se consigue a través del sufrimiento. Y lo que desea es trascender el principium individuationis, trascender su personalidad, para poder fundirse con el todo, a la manera oriental, o bien, siguiendo una vía occidental, poder superar la circunstancia que le limita colocándose en un plano supratemporal en comunión con los Inmortales, esto es, las grandes figuras del arte, que incluyen, entre otros, a los reverenciados Goethe y Mozart. La unidad, deja claro Hesse, no se encuentra en el individuo, la unidad es siempre trascendente. De ahí que el individualismo estrecho burgués sea desechado a favor de un individualismo o, mejor, subjetivismo, que pretende ensanchar tanto al yo que éste se acaba disolviendo.

\section{CONCLUSIÓN}

En suma, Hesse construyó un personaje en El lobo estepario a imagen y semejanza de sí mismo y en consonancia con su propia identidad como artista, que bebe de la tradición romántica y se basa en una equiparación del artista con el genio o el loco, así como en la oposición irreconciliable entre el artista y el filisteo, el enemigo mortal del primero. Se trata, explica Eckhardt Neumann en Mitos de artista, de una sacralización del artista, quien sucede al héroe cristiano y da lugar a una religión de arte. En sus palabras: 
«[...] el genio romántico encarna la condición extraña al mundo, en tanto que se considera profeta de espíritu trascendental en contraposición al mundo de los burgueses que está determinado por las leyes del comercio. Como antípoda del filisteo simboliza el fatal dualismo de espíritu y materia, del que a partir de entonces debe crecer el mito de la alienación y la incapacidad para el mundo del artista»54

Con una concepción tal del arte y el artista —pues él se consideraba artista, Dichter, palabra que posee connotaciones sacras ${ }^{55}$ - es natural que Hesse se construyera a sí mismo y construyera a sus personajes como outsiders: no cabía otra opción, si a ese concepto de artista se le suma toda su herencia religiosa pietista y su propia personalidad tan bien caracterizada en sus novelas. Sin embargo, la alienación que él refleja en sus obras y las crisis que sufren sus personajes no eran vivencias privativas de los artistas. Su obra conectó con millones de lectores que se sintieron concernidos y, tal vez, reflejados, y que invistieron a su autor de la autoridad moral de un profeta, pues entendían que el artista les estaba mostrando vías para construir una vida con sentido, así como una identidad que les permitiera encontrar su lugar en el mundo (o, al menos, en el cosmos). Que se convirtiera en un autor de culto preferentemente entre adolescentes y jóvenes no tiene mayor misterio: en sus obras casi todos los personajes lo son, y todos ellos -incluyendo los que no lo son-, están concentrados como casi única actividad en la tarea de encontrarse a sí mismos, de construir una identidad al margen del mundo adulto, como estaban haciendo tantos jóvenes lectores. Y además Hesse supo adelantarse a corrientes posteriores, desde la contracultura y los distintos movimientos de liberación de los sesenta, hasta la llamada «revolución silenciosa» que, de acuerdo con el célebre diagnóstico de Ronald Inglehart, ha transformado los valores en los países desarrollados, que se han vuelto progresivamente postmaterialistas a medida que las nuevas generaciones podían dar por descontado el bienestar material y orientarse hacia otras metas superiores, pasando por el revival religioso al que se suele dar el nombre de New Age. A estas corrientes hay que añadir todas las subculturas juveniles que hacen de la «liminaridad», por utilizar el término del antropólogo Victor Turner, un modo de vida y una identidad durante cada vez más años, un fenómeno que parece haberse consolidado en las sociedades desarrolladas. Pero la cuestión de la recepción de la obra de Hesse y de las afinidades entre ella y los valores de las distintas generaciones de lectores es un tema para otro artículo.

${ }^{54}$ NEUMANN, Eckhard, Mitos de artista. Estudio psicohistórico sobre la creatividad, Madrid, Tecnos, 1992, p. 76.

${ }_{55}$ Para una contraposición entre las figuras del Dichter y el escritor (Schriftsteller), y un tratamiento del caso de Hesse y su posición hacia la política, vid. mi artículo: MARTÍNEZ SAHUQUILLO, Irene, «El literato frente a la política: entre el repudio aristocrático, el compromiso militante y la crítica al poder ", Política y Sociedad, vol. 44, oㅜ 3, 2007, pp. 163-182. 